\title{
Development of Commonsense Knowledge Modeling
} System for Psychological Assessment in Clinical Psycho

\author{
D.S. Kalana Mendis ${ }^{1}$, Asoka S. Karunananda ${ }^{2}$, Udaya Samaratunga ${ }^{3}$ and U. Rathnayake ${ }^{4}$ \\ 1. Department of Information Technology, Advanced Technological Institute, Dehiwala 10350, Sri Lanka \\ 2. Faculty of Information Technology, University of Moratuwa, Moratuwa 10400, Sri Lanka \\ 3. Gampaha Wickramarrachi Ayurveda Institute, University of Kelaniya, Kelaniya 11600, Sri Lanka \\ 4. Department of Electrical \& Computer Engineering, Open University of Sri Lanka, Nawala 10250, Sri Lanka
}

Received: October 15, 2013 / Accepted: November 26, 2013 / Published: January 31, 2014.

\begin{abstract}
According to the Buddhist philosophy, hatred (dosa) is considered as one of the three unwholesome roots which determine the actual immoral quality of volitional states and a conscious thought with its mental factors. Hatred, then, comprises all degrees of repulsion from the faintest trace of ill-humour up to the highest pitch of hate and wrath. Thus, ill-will, evil intention, wickedness, corruption and malice are various expressions and degrees of dosa. A hateful temperament is said to be due to a predominance of the type of dosa, apo, vayu and semha. Vedic psychology forms the clinical core of mental health counseling in the Ayurvedic medical tradition. According to Ayurvedic medical practises, a person is dominated on one of constitutes type (type of dosa) namely vata (vayu), pita (apo) or kapha (semha). This is known as prakurthi pariksha. Important aspect of identification of constitute type is for diagnosis of mental diseases, because each of constituent type has a list of probable mental diseases. An important area of expertise for many clinical psychologists is psychological assessment. Constructions of information systems using psychological assessment in clinical psychology have a problem of effective communication because of implicit knowledge. This complicates the effective communication of clinical data to the psychologist. In this paper, it presents an approach to modeling commonsense knowledge in clinical psychology in Ayurvedic medicine. It gives three-phase an approach for modeling commonsense knowledge in psychological assessment which enables holistic approach for clinical psychology. Evaluation of the system has shown $77 \%$ accuracy.
\end{abstract}

Key words: Human constituents, psychological assessment, clinical psychology, Ayurvedic medicine, commonsense knowledge modeling system.

\section{Dosa}

Dosa, which means malice, harted, ill-will, is one of the three root-causes of unskillful or un-wholesome actions (akusala-mula). It is consisted of greed (loba), harted (dosa) and delusion (moha) as stated in Buddhist philosophy [1]. But, whereas delusion is found in any unwholesome deed or thoughts, greed and hatred stand as two opposites, as attraction and repulsion, respectively. Hatred, then, comprises of repulsion from the faintest trace of ill-humor up to the highest pitch of

Corresponding author: D.S. Kalana Mendis, Ph.D., research field: forensic psychiatry. E-mail: kalanaatil@mail.com. hate and wrath. Thus, ill-will, evil intention, wickedness, corruption and malice are but various expression and degrees of dosa. Hate, of course, is inspired by wrong views (miccha-ditthi), for, if things are seen and understood in their proper perspectives, no ill feeling can arise. Envy (issa), selfishness (macchariya) and worry (kukkucaa) are always associated with hatred or ill-will (dosa). Sometimes, obduracy (thina) and sluggishness (middh) are closely connected with certain forms of hatred [1].

A hateful temperament is said to be due to a predominance of the elements cohesion (apo) and 
oscillation (vayu) and also to a preponderance of phlegm (semha) over the other humours in the body. Hatred is paraphrased in Abhidhama terminology as a disordred temper, getting upset, a feeling of disgust, throwing off of a normal state and the abrupt reaction of rage. It is annoyance (aghata) at the thought of harm done to oneself or to someone dear or good done to a person disliked. It may spring up as vexation due to climatic conditions which prove a momentary obstacle, such as the wind preventing one to dress. This would lead to resentment (patighata) and repugnance (patigha), and the latter is being more a passive state of sense-reaction [1].

\section{Ayurvedic Classification of Individuals}

Ayurvedic medicine has a very strong bearing on the concept of Prakurthi, which means nature (natural form) of the build and constitution of the human body [2]. This has been evolved with Hatred (dosa), one of the three unwholesome roots which determine the actual immoral quality of volitional states and a conscious thought with its mental factors [1, 3-9]. A hateful temperament is said to be due to a predominance of the type of dosa, apo, vayu and semha for diagnosing mental diseases. According to Ayurveda, the path to optimal health is different for people depending on their Prakruti. For individuals, the Prakurthi is defined as a combination of (vatha, pittha and kapha) [10]. A balanced state of the Prakurthi makes a healthy and balanced person (physically and mentally). Since the authors all have different combinations of the Prakurthi. The diagnosis of prakruti offers unique insights into understanding and assessing one's health. It is not merely a diagnostic device but also a guide to action for good health. It assesses the, dominance of Prakurthi and gives advice for preventive and primitive health care. The ancient science of Ayurveda is the oldest known form of health care in the world. Important aspect of identification of constitute type is for diagnosis of mental diseases, because each of constituent type has a list of probable mental diseases
[10-14] such as an important area of expertise for many clinical psychologists which is psychological assessment (Table 1).

\section{Psychological Assessment in Clinical Psychology}

Clinical psychology is an integration of science, theory and clinical knowledge for the purpose of understanding, preventing, and relieving psychologically based distress or dysfunction and to promote subjective well-being and personal development. Central to its practice are psychological assessment and psychotherapy, although clinical psychologists also engage in research, teaching, consultation, forensic testimony, and program development and administration. In many countries, clinical psychology is a regulated mental health profession. Psychological Assessment is concerned mainly with empirical research on measurement and evaluation relevant to the broad field of clinical psychology. The areas of assessment processes and methods are included as given below [15]:

- Clinical judgment and the application of decision-making models;

- Paradigms derived from basic psychological research in cognition, personality-social psychology, and biological psychology;

- Development, validation, and application of assessment instruments, observational methods, and interviews.

\section{Psychological Assessment in Clinical Psychology of Ayurvedic Medicine}

Recognition of human constituent in Ayurveda, is currently based on a standard questionnaire on subjective criteria based on ancient theories of Ayurvedic scholar Charaka, 1000 BC and Susruta, $600 \mathrm{BC}[10]$ as a psychological assessment in clinical

Table 1 Classification of mental diseases.

\begin{tabular}{|l|l|l|}
\hline vata & pittha & kapha \\
\hline anxiety disorders & anger disorders & depression disorders \\
\hline
\end{tabular}


psychology. Classification of individuals through clinical examination in Ayurveda has been considered [16]. The clinical examination of Ayurveda is divided into two paths, namely: examination through patient and examination through disease. Prescribing drugs for a disease is depended on both two examinations. Classification of individual (human constituents) is included in examination through patient, which defined as a concept called "prakurti pariksha". Individual can be categorized into vata or pita or kapha based on the "prakurti pariksha". It was defined that one type can be dominated but in combination of all 3 types. Chopra Center [17] built a web base system to discover the type of body constituent type. A questionnaire is used to diagnose constituent type. This dosa centre also built a web based system based on a questionnaire to predict type of prakurthi $[18,19]$. There was also a web system to evaluate type of prakurthi based on a questionnaire and predict percentage of relevant type of prakurthi [20].

In exciting systems, the method of analyzing constituents is not consistent. Questions in concerned are very much user-friendly and based on medical theories of Ayurveda, which is used for finding constituent type and probes such as repeating questions and classification of constituent type and its possible mental diseases. Anxiety disorders are depended on vata constituent type. This has been used for classification of individuals for many centuries. There is no research into improving the questionnaire although people have realized that the classification is not acceptable sometimes.

David Paul built an approach for collaborative activities in virtual settings enabling the different parties to achieve their desired objectives by examining them from a knowledge management perspective in tele medicine [21]. Dwivedi et al. could make web-based multimedia patient administration systems be the norm for healthcare institutions. Such a scenario is likely to lead to a situation where healthcare institutions would be flooded with large amounts of clinical data. The introduction of the KM (knowledge management) paradigm would enable healthcare institutions to face the challenge of transforming large amounts of medical data into relevant clinical information. A KM solution would allow healthcare institutions to give clinical data context, so as to allow knowledge derivation for more effective clinical diagnoses [22]. Kimble Chris presented a framework for categorizing virtual teams and argued that fundamental changes have taken place in the business environment which force people and organizations to operate in "two spaces" simultaneously: the physical space and the electronic space. It highlighted some of the issues of trust and identity that existed in virtual teams and argued that, due to certain barriers, only a small proportion of these teams reached a satisfactory level of performance. Using the evidence from two recent sets of studies, it highlighted some of the barriers to effective virtual team working and demonstrateed the critical importance of trust and social bonding to the functioning of such teams. It reported on the use of a "Community of Practice" in a virtual team and argued that this may provide one mechanism for overcoming some of the barriers [23]. Julie Parker and Enrico reviewed improving clinical communication for a cognitive psychological perspective, focusing on current understandings of how human memory functions and on the potential consequences of interruptions on the ability to work effectively. It was concludeed by discussing possible communication technology interventions that could be introduced to improve the clinical communication environment [24]. Richard Lenz elaborated both the potential and the essential limitations of IT support for healthcare processes. It has been identified different levels of process support in healthcare, and distinguished between organizational processes and the medical treatment process. To recognize the limitations of IT support, it has been adopted a broad socio-technical perspective based on scientific literature and personal experience [25]. Fallowfield discussed some of the 
issues that influenced communication within an oncology setting, and ultimately affect patient. Oncologists themselves acknowledge that insufficient training in communication and management skills is a major factor contributing to their own stress, lack of job satisfaction and emotional burnout. Consequently, over the past few years there have been several initiatives aimed at improving basic communication skills training for healthcare professionals in the cancer field [26]. Mario Stefanelli discussed the role of mobile communication systems. Moreover, the paper discussed the role of mobile communication and speech understanding technologies to support a satisfactory user-system interaction in daily work [27].

Using psychological assessment in clinical psychology had a problem of effective communication because of implicit knowledge for constructing Information systems. This complicated the effective communication of clinical data to the psychologist in support of clinical psychology.

As such the authors decided to resolve the problem with the help of AI (Artificial Intelligent) techniques. An approach as Mark suggested has been explored in a program called OPAL, which allows medical specialists working alone to enter and review cancer treatment plans for use by an expert system called ONCOCIN. Knowledge-acquisition tools based on strong domain models should be useful in application areas whose structure is well understood and for which there is a need for repetitive knowledge entry [28]. Ramoni, MT model accounted for all of the conceptual features of knowledge-based systems, thus making clear which features were intrinsic to the problem and which were artifacts of the implementation. The proposal was based on a two-level analysis of knowledge-based systems: an epistemological and a computational level [29]. James proposed that a generalization of the set covering problem can be used as an intuitively plausible model for diagnostic problem solving. Such a model was potentially useful as a basis for expert systems in that it provided a solution to the difficult problem of multiple simultaneous disorders [30]. John Protégé-2000, could be run on a variety of platforms, supported customized user-interface extensions, incorporates the OKBC (Open Knowledge-Base Connectivity) knowledge model, interacted with standard storage formats such as relational databases, XML, and RDF. Using Protégé, developers and domain experts could easily build effective knowledge-based systems, and researchers could explore ideas in a variety of knowledge-based domains [31]. So it is well known fact that Expert systems are better at solving real world problems, which cannot be solved otherwise [32-38]. In particular Expert systems can be used to models domains with less formal knowledge [39-42].

\section{Commonsence Knowledge Modeling System}

In this paper an approach was presented to model commonsense knowledge in psychological assessment for clinical psychology in Ayurvedic medicine evolved by dosa in Buddhist studies [43-45] using an Expert system based on principal component analysis and statistical fuzzy inference system. Dosa in Buddhist studies stated that ill-will, evil intention, wickedness, corruption and malice are various expressions and degrees of dosa and hateful temperament is said to be due to a predominance of the type of dosa, apo, vayu and semha. This gives knowledge modeling approach for modeling commonsense knowledge in, psychological assessment which enables holistic approach for clinical psychology to find:

- Type of dosa (constituent type: vata, pitta, kapha) in percentages;

- Dominant type of dosa;

- Possible metal disease based on type of dosa.

Principal component analysis is used for exploring data to reduce the dimension. Generally, PCA (principal component analysis) seeks to represent $n$ correlated random variables by a reduced set of uncorrelated variables, which are obtained by 
transformation of the original set onto an appropriate subspace. The uncorrelated variables are chosen to be good linear combination of the original variables, in terms of explaining maximal variance, orthogonal directions in the data. Two closely related techniques, principal component analysis and factor analysis, are used to reduce the dimensionality of multivariate data. In these techniques correlations and interactions among the variables are summarized in terms of a small number of underlying factors. The methods rapidly identify key variables or groups of variables that control the system under study. The resulting dimension reduction also permits graphical representation of the data so that significant relationships among observations or samples can be identified.

Other techniques include multidimensional scaling, cluster analysis, and correspondence analysis.

- MDS (multidimensional scaling) is a set of related statistical techniques often used in information visualization for exploring similarities or dissimilarities in data;

- Cluster analysis or clustering is the assignment of a set of observations into subsets (called clusters) so that observations in the same cluster are similar in some sense;

- CA (correspondence analysis) is a multivariate statistical technique proposed by Hirschfeld and later developed by Jean-Paul Benzécri. It is conceptually similar to principal component analysis, but applies to categorical rather than continuous data. In a similar manner to principal component analysis, it provides a means of displaying or summarizing a set of data in two-dimensional graphical form [46-48].

Inference is the act or process of deriving logical conclusions from premises known or assumed to be true. The conclusion drawn is also called an inference. The laws of valid inference are studied in the field of logic. Human inference (i.e., how humans draw conclusions) is traditionally studied within the field of cognitive psychology; artificial intelligence researchers develop automated inference systems to emulate human inference. AI systems first provided automated logical inference and these were once extremely popular research topics, leading to industrial applications under the form of expert systems and later business rule engines. Bayesian inference has applications in artificial intelligence and expert systems. Bayesian inference techniques have been a fundamental part of computerized pattern recognition techniques since the late 1950s. There is also an ever growing connection between Bayesian methods and simulation-based Monte Carlo techniques since complex models cannot be processed in closed form by a Bayesian analysis, while a graphical model structure may allow for efficient simulation algorithms like the Gibbs sampling and other Metropolis-Hastings algorithm schemes. Recently Bayesian inference has gained popularity amongst the phylogenetics community for these reasons; a number of applications allow many demographic and evolutionary parameters to be estimated simultaneously. In the areas of population genetics and dynamical systems theory $\mathrm{ABC}$ (approximate Bayesian computation) are also becoming increasingly popular [49].

Bayesian inference is a method of statistical inference in which evidence is used to estimate the probability that a hypothesis is true. The term "Bayesian" comes from the application of Bayes' theorem to probabilities that specifically have the interpretation as Bayesian probabilities. Such probabilities can themselves be distinguished into objective and subjective probabilities. In practical usage, "Bayesian inference" refers to an iterative process in which collection of fresh evidence repeatedly modifies an initial confidence in the truth of a hypothesis. In each iteration, the initial belief is called the prior probability, whereas the modified belief is called the posterior probability. Fuzzy logic is an alternative to Bayesian inference. Fuzzy logic and Bayesian inference, however, are mathematically and 
semantically not compatible [50]. You cannot, in general, understand the degree of truth in fuzzy logic as probability and vice versa; fuzziness measures "the degree to which an event occurs, not whether it occurs" $[49,51]$.

Fuzzy logic and probability are different ways of expressing uncertainty $[52,53]$. While both fuzzy logic and probability theory can be used to represent subjective belief, fuzzy set theory uses the concept of fuzzy set membership (i.e., how much a variable is in a set), and probability theory uses the concept of subjective probability (i.e., how probable do I think that a variable is in a set). While this distinction is mostly philosophical, the fuzzy-logic-derived possibility measure is inherently different from the probability measure, hence they are not directly equivalent. While this distinction is mostly philosophical, the fuzzy-logic-derived possibility measure is inherently different from the probability measure, hence they are not directly equivalent.

In the first place, the authors have tried statistical technique of PC (principal component) analysis [54] for recognition of any dependencies among classification of individuals using the questionnaire as a psychological assessment. Among other AI techniques, the authors have used Fuzzy logic [55] to fine tune the results obtained from PC analysis. Finally the system has been developed as an Expert System [56], which models Ayurvedic classification of individuals. With this technology the system has added features such as incorporating new knowledge, explaining reasons for answers given.

\section{Methods}

The authors postulate a new approach enhancing the ability of classifying human constituents using an expert system based on principal component analysis and Fuzzy logic. It has been extended from constructions of membership functions [33, 45] to statically based defuzzification process. This has been exploited the process of the new approach in following steps.

\subsection{Removing Dependencies}

The approach begins by acquiring commonsense knowledge. This can be done as an interview between domain experts and the knowledge engineer. Using the interviewing process between expert and knowledge engineer, commonsense knowledge has been acquired and mapped in to a questionnaire based on Likert scale technology [57]. The authors have chosen to acquire tacit knowledge into a questionnaire since it is more convenient for further analysis. On the other hand, the questionnaire can be automated to interact directly with the domain expert without involving a knowledge engineer. Once tacit knowledge has been acquired then the knowledge for finding dependencies should be analyzed. The questionnaire has been analyzed using PC (principal component) analysis [54] to find dependencies.

- What is PC analysis?

The concept of PC analysis is based on the derivation of linear combinations of the $p$ measured variables $X_{1}, X_{2}, \ldots X_{p}$ to produce "derived variables", that are uncorrelated and are such that explains a different "dimension" within the data [54]. Such derived variables are referred to as PCs (principal components). As there are $p$ response variables within the data set, $p$ principal components can be derived. The first $P C$, denoted $P C 1$, is expressed in the form

$$
P C_{1}=\alpha_{11} X_{1}+\alpha_{12} X_{2}+\ldots .+\alpha_{1 p} X_{p}
$$

where, the $\alpha$ terms refers to the weight of each variable within this principal component $P C_{l}$. The weights of each $P C_{i}$ represent the eigenvector solution, which maximize the variance of each $P C_{i}$, where $i$ is the number of components [35].

- Extracting principal components

The importance of each $P C$, in terms of level of data variation explained, is specified by its eigenvalue, the $\lambda$ term, with $\Sigma \lambda$ representing the total of the $p$ eigen values. A measure of the proportion of data variation accounted for by each $P C$, based on the equivalence of eigenvalue and $P C$ variance, is provided by the expression $\lambda /(\Sigma \lambda)$. 
Generally, it is required to select those $P C s$, which account cumulatively for at least $80 \%$ to $90 \%$ of the data variation. In addition, each $P C$ must exceed eigenvalue more than 1 . However, if nearly all the correlations are less than 0.25 , there is probably no purpose in carrying out a PCA. However, to reduce even that much of interdependency $P C s$ can be computed.

- $P C$ for commonsense knowledge modeling (model refinement)

Let $S$ be the set of all questions in the questionnaire and $P$ be the set of all extracted principal components.

Further,

$$
\begin{gathered}
P=\left\{P C_{1}, P C_{2}, . . P C_{p}, P C_{p+1} \ldots P C_{r}, P C_{r+1}\right. \\
\left.\ldots P C_{n-1}, P C_{n}\right\} \\
S=\left\{S_{1}, S_{2}, . . S_{q}, S_{q+1}, \ldots S_{s}, S_{s+1}, \ldots S_{m-1}, S_{m}\right\} \\
P C_{i}=a_{1 i} S_{1}+a_{2 i} S_{2}+\ldots a_{q i} S_{q}+a_{q+1, i} S_{q+1}+ \\
\ldots a_{s i} S_{s}+a_{s+1, i} S_{s+1}+\ldots a_{m-1, i} S_{m-1}+a_{m, i} S_{m}
\end{gathered}
$$

Let $M$ be the principal components Matrix for filtered commonsense knowledge.

$$
M=\left[\begin{array}{l}
a_{11} a_{12} \ldots a_{1 p} a_{1 p+1}, \ldots a_{1 r} a_{1 r+1} \ldots a_{1 n} \\
a_{21} a_{22} \ldots a_{2 p} a_{2 p+1} \ldots a_{2 r} a_{2 r+1} \ldots a_{2 n} \\
\cdot \\
a_{m 1} a_{m 2} \ldots a_{m p} a_{m p+1}, a_{m r} a_{m r+1} \ldots a_{m n}
\end{array}\right]
$$

For $n$ number of extracted principal components, following computation is concluded.

$$
\begin{gathered}
X=\sum_{j=1}^{n} P C_{j} \\
X=\sum_{j=1}^{n} \sum_{i=1}^{m} a_{i j} S_{i} \\
\mathrm{X}=\sum_{j=1}^{p} \sum_{i=1}^{q} a_{i j} S_{i}+\sum_{j=p+1}^{r} \sum_{i=q+1}^{s} a_{i j} S_{i}+\sum_{j=r+1}^{n} \sum_{i=s+1}^{m} a_{i j} S_{i}
\end{gathered}
$$

Let $L S$ be the Likert scale [11], then

$$
L S=[L, . ., U]
$$

$X_{L}$ and $X_{U}$ values are derived from results of the filtered commonsense knowledge using principal component analysis. It is computed as given below

$$
\begin{gathered}
X=\left[X_{L} \ldots X_{U}\right] \\
X=\left[\begin{array}{l}
\left(X_{L 1} \ldots X_{U 1}\right),\left(X_{L 2} \ldots X_{U 2}\right), \ldots . . \\
\left(X_{L n} \ldots X_{U n}\right)
\end{array}\right] \\
X_{L n}=L_{n} \sum_{j=i+1 i=s+1}^{n} \sum_{i j}^{m} a_{i n} \\
X_{U n}=U_{n} \sum_{j=i+l i=s+1}^{n} a_{i j}
\end{gathered}
$$

\subsection{Statistical Fuzzy Inference-(Fine Tuning)}

This phase is constructed by integrating output of model refinement with fuzzy inference system. It is consisted with following stages:

\section{- Fuzzfication}

In this sub phase of fuzzification, it basically analysis the fuzzy set and membership function for commonsense knowledge modeling. Membership functions have been constructed by using output of model refinement.

Let $A$ be fuzzy set defined on a fuzzy concept using the interval of

$$
\left[\left(X_{L 1} \ldots X_{U 1}\right),\left(X_{L 2} \ldots X_{U 2}\right), \ldots,\left(X_{L n} \ldots X_{U n}\right)\right]
$$

Membership functions are defined as follows:

$$
\begin{aligned}
& \text { For } L_{n}=\left[X_{L n} \ldots X_{U n}\right] \\
& A_{n}(X)=\left(\frac{X-X_{L n}}{X_{L n}-X_{U n}}\right)
\end{aligned}
$$

- Fuzzy rule base

Fuzzy rule base has been constructed by using the membership functions defined in fuzzification process.

Fuzzy rules can be constructed as follows,

$$
\begin{array}{cc}
\text { Rule n. If } & X>X_{L n} \quad \text { AND } \quad X<X_{U n} \\
& A_{n}(X)=\left(\frac{X-X_{L n}}{X_{U n}-X_{L n}}\right)
\end{array}
$$

Adding dynamically, in order to operate the reasoning process for answers given by the fuzzy rules, it can extend further in to a fuzzy rule base.

Here $K_{1}, K_{2} \ldots K_{n}$ are defined as singleton fuzzy sets 


$$
\begin{aligned}
K_{n}= & \frac{\left(X_{U n}-X_{L n}\right)}{\left(X_{U 1}-X_{L 1}\right)+\left(X_{U 2}-X_{L 2}\right)+\ldots} \\
& \left(X_{U n}-X_{U 2}\right)
\end{aligned}
$$

- Defuzzification

The input for the defuzzification process is a fuzzy set (the aggregate output fuzzy set) and the output is a single number. As much as fuzziness helps the rule evaluation during the intermediate steps, the final desired output for each variable is generally a single number. However, the aggregate of a fuzzy set encompasses a range of output values, and so must be defuzzified in order to resolve a single output value from the set. Defuzzification has been implemented using Sugeno-Type Fuzzy Inference [58].

Here $K_{1}, K_{2}, \ldots, K_{n}$ are defined as singleton fuzzy sets.

$$
\text { Rule n. If } \begin{aligned}
A_{n}(X) & =\left(\frac{X-X_{L n}}{X_{U n}-X_{L n}}\right) \\
Z & =K_{n}
\end{aligned}
$$

Let $Z$ be the output of rules defined in Sugeno-Type fuzzy inference

$$
Z=\frac{A_{1}(X) * K_{1}+A_{2}(X) * K_{2}+\ldots+A_{n}(X) * K_{n}}{A_{1}(X)+A_{2}(X)+\ldots+A_{n}(X)}
$$

\section{Framework for Commonsence Knowledge Modeling System}

The framework for modelling of commonsense knowledge has been developed on the basis of phases mentioned above. Such the framework enables $P C$ analysis, knowledge classification and intelligent reasoning using the expert system technology.

Functionally the entire system can be seen as a fuzzy-expert system. Fig. 1 shows the top-level architecture of the framework. It consists of a user interface, inference engine, knowledge base, fuzzy logic module, principal component analyzer and a database.

Commonsense knowledge has been extracted from the expert and formulated in a questionnaire. It is evaluated using Likert scale technology. In the first

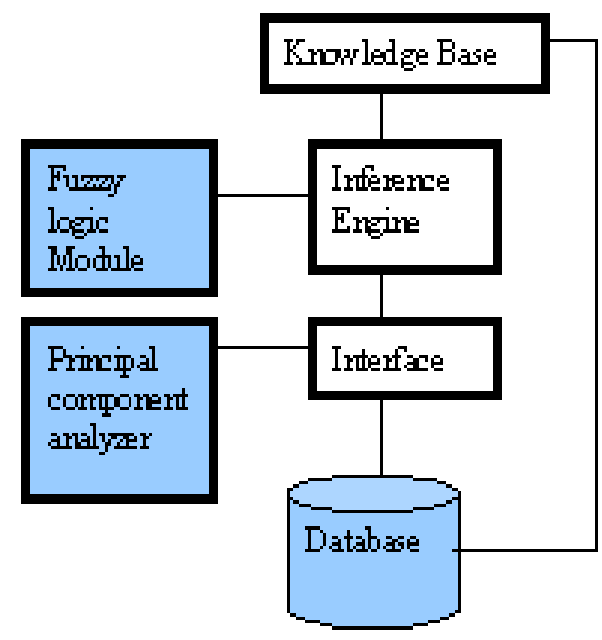

Fig. 1 Top level architecture of system.

instance of knowledge acquisition, a pilot survey has been done for the purpose of extracting principal components. The SPSS is used for conducting the functions of principal components extracting.

\subsection{Fuzzy Logic Module}

The output results of the principal component analyzer would be the input for the fuzzy logic module. In the case of generating membership function, finding the interval is considered as an automated process in this module due to instead of using runtime inputs. This module has been implemented using Visual Basic for widening scope of generating membership function. Further, fuzzy rules have been constructed in the fuzzy logic module.

\subsection{Database}

Extracted principal components have been stored in Ms Access database, which integrated with the principal component analyzer through the developer interface that is considered as a sub interface of the user interface. The questionnaire consisted of tacit knowledge also has been stored in the database that integrated with the user interface.

\subsection{Knowledge Base}

Explanations for output generated by the fuzzy logic module have been processed using fuzzy rules in the 


\section{Development of Commonsense knowledge Modeling System for Psychological Assessment in Clinical Psycho}

knowledge base. Further, knowledge engineer is given a facility to add new rules in the runtime. The knowledge base has been implemented using FLEX expert system shell, which embedded in Win-Prolog.

\subsection{User Interface}

The user interface facilitates for both developer and general user. Once knowledge engineer develops a particular framework for required tacit domain with interaction of the expert, and then general user will be given a facility of using the framework for decision-making purposes. So, it has been divided the user interface in developer interface and general user interface. General user will be able to use a developed framework using a questionnaire, which has been implemented as a web page linked to the database.

\subsection{Inference Engine}

The inference engine carries out the reasoning whereby the expert system reaches a solution. This is the inference engine of the FLEX expert system shell. Since this is built in to the system, there is no development activity with regard to this component in the system. Note that inference engine has nothing to do with the modeling of commonsense knowledge but it runs the expert system.

\section{System in Practice}

In the exciting system, the method of analyzing constituents is not consistent. Although Ayurvedic practitioners use a psychological questionnaire, it leads to several problems like dependencies among the questions in the questionnaire and analysis of the constituent type. These problems were addressed to solve using following stages.

\subsection{Extracting Commonsense Knowledge in Ayurveda}

In the first instance, the authors mapped commonsense knowledge regarding to analysis of constituents to a (psychological assessment) questionnaire with interaction of an Ayurvedic expert.
It is consisted of 72 questions to analyze vata, pita and kapha. It is certainly need to measure attitudes during the practical communication work. The questionnaire can be produced very rapidly on Access database (Table 2):

\subsection{Removing Dependencies}

The authors have done a pilot survey using 100 No. of students for statistical modeling. Principal component analyzer has been used to remove dependencies. It has been identified 25 principal components using SPSS [59] as shown below in a matrix form (Fig. 2). Here $V 1, V 2, V 24, K 1, K 2, \ldots$, $K 24, P 1, P 2, \ldots, P 24$ denote question-numbering system in the questionnaire.

Human constituents can be computed in to vata, pita and kapha in percentages as shown in Fig. 3. Membership functions for vata, pita and kapha have been constructed using the out puts of principal component analyzer.

For example, Membership function for Vata constitution

Table 2 A part of 72 numbers of questions in the questionnaire.

\begin{tabular}{lll}
\hline ID & Question & Marks-range Marks \\
\hline 1 & My skin is cracked, dry and cold & $1-6$ \\
2 & On my skin, vains and tendons are & $1-6$ \\
& easily visible & $1-6$ \\
3 & I am tend to be slight sweating & $1-6$ \\
4 & I have less body smell & $1-6$ \\
5 & Under developed body build & $1-6$ \\
6 & I do not gain weight very easily & $1-6$ \\
\hline
\end{tabular}

Respondents are required to enter their answers directly at the computer

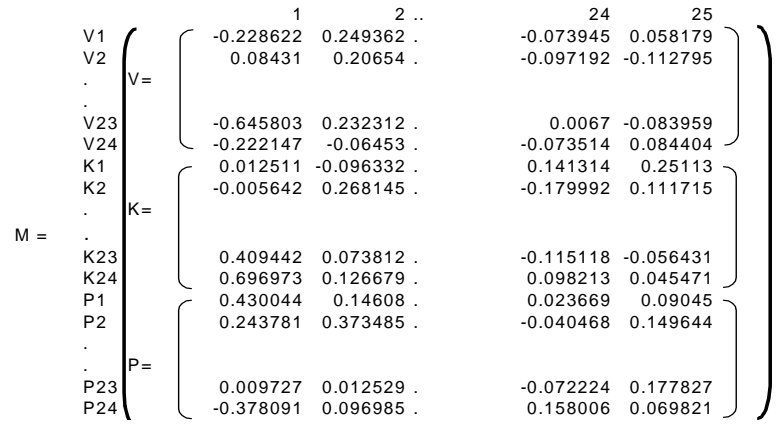

Fig. 2 Principal components identified in the system. 


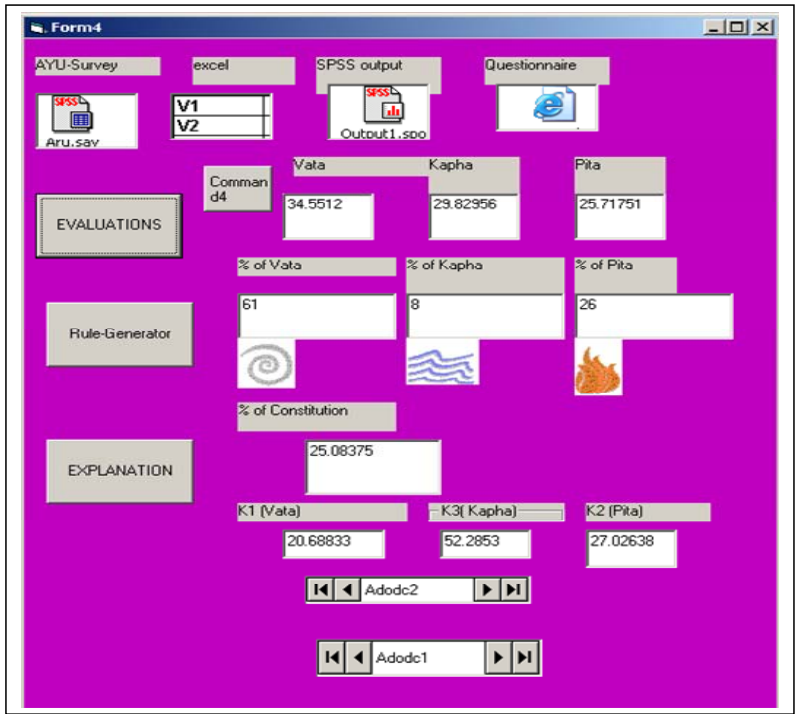

Fig. 3 Analysis of human constituents.

$$
\begin{gathered}
\text { For } L_{1}=\left[X_{L 1} \ldots X_{U 1}\right] \\
\because X_{L}=1 \sum_{i=1}^{25} \sum_{j=1}^{24} a_{j i}=8.510004 \\
\because X_{U}=6 \sum_{i=1}^{25} \sum_{j=1}^{24} a_{j i}=51.06002 \\
A_{1}(X)=\left(\frac{X-8.510004}{51.06002-8.510004}\right)
\end{gathered}
$$

\subsection{Fuzzy Rule Base}

Fuzzy rules have been constructed for classification of each of constituent's type.

For example, Vata constitution

Rule 1. If $X>8.510004$ and $X<51.06002$

$$
A_{1}(X)=\left(\frac{X-8.510004}{51.06002-8.510004}\right)
$$

- Defuzzification

Defuzzification process has been computed using Sugne-style inference technique:

Here $K_{1}, K_{2}, K_{3}$ are defined as singleton fuzzy sets.

For example, vata constitution

$K_{l}=42.550016 /(55.5856+107.53602+42.550016)$ $=20.68833$.

For example, vata constitution

Rule 1. If $A_{1}(X)=\left(\frac{X-8.510004}{51.06002-8.510004}\right)$ then $K_{I}=20.68833$.

This computation will defuzzify the output of defuzzification process as 25.08375 .

Further $K_{1}, K_{2}, K_{3}$ are defined as singleton fuzzy sets.

For vata constitution,

$K_{I}=42.550016 /(55.5856+107.53602+42.550016)$

$=20.68833$.

For pitta constitution,

$K_{2}=107.53602 /(55.5856+107.53602+42.550016)$ $=27.02638$.

For kapha constitution,

$K_{3}=55.5856 /(55.5856+107.53602+42.550016)=$ 52.2853 .

$$
\begin{aligned}
& Z=\frac{A_{1}(X) * K_{1}+A_{2}(X) * K_{3}+. A_{3}(X) * K_{2}}{A_{1}(X)+A_{2}(X)+A_{3}(X)} * 100(23) \\
& Z=\text { out put }=25.08375 .
\end{aligned}
$$

So body constitution is concluded as value between vata and pitta.

By clicking explanation button in Fig. 3, it will show an output analysis and window (Fig. 4) of completed evaluation. This has been implemented using FLEX expert system shell [60].

This evaluation is consisted with:

- Vata, kapha, pita are in a combination (\%);

- Determination of dominated constituent type.

\subsection{Explanations for Derived Human Constituents}

Explanations for output generated by the fuzzy logic module have been processed using fuzzy rules in the knowledge base in the expert system. The knowledge base has been implemented using FLEX expert system shell, which embedded in Win-Prolog. In relation to Ayurvedic domain, possible mental diseases can be occurred due to dominated constituent type (dosa). It is illustrated as shown in Fig. 4.

\section{Analysis of Results}

The authors set up their evaluation criterion as a comparison between the system and a real world expert in the similar domain. Both Ayurvedic expert and the system have been used to investigate human constitutions separately. 


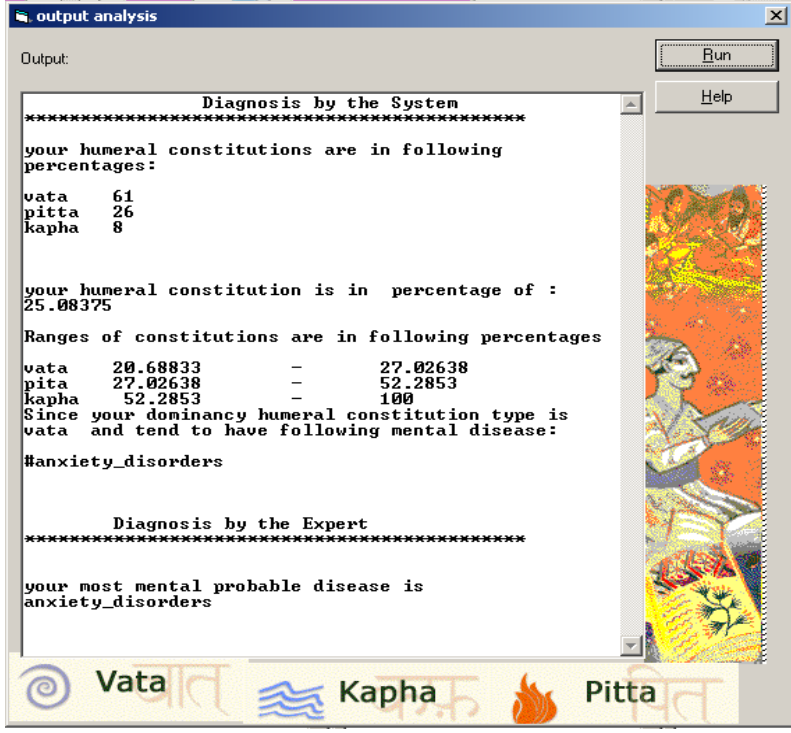

Fig. 4 Analysis and reasoning window in Ayurvedic domain constructed using FLEX.

The layman-expert and layman-system have been set. up into two groups. Here layman is considered as a general person without having specific knowledge of Ayurveda. It has been taken 30 numbers of laymen as a sample. Here expert is considered as an expertise person in Ayurvedic domain. System denotes the implemented expert system for domains with tacit knowledge. The evaluation was based on investigating humeral constitutions as per layman using two groups considered for the evaluation criteria. The layman, Ayurvedic expert and system are referred as $L, E$ and Sys, respectively.

The layman-Ayurvedic Expert and layman-System interactions can be comprehended by a figure as in Fig. 5 .

Arranging the setup as depicted in Figure 5 enables $\mathrm{E}$ to compare the differences between the interactions with layman-Ayurvedic expert and layman-System. The Ayurvedic expert's feeling towards the use of the system and the layman for his/her humeral constitution is evaluated thereafter.

The key feature required to evaluate in the system is whether the system derives a conclusion equaling a conclusion derived by an expert who works with the same domain. Here, modeling behavior of a conclusion derived from a particular selected domain in to a further analysis is expected. In this sense, aspects viz was tested.

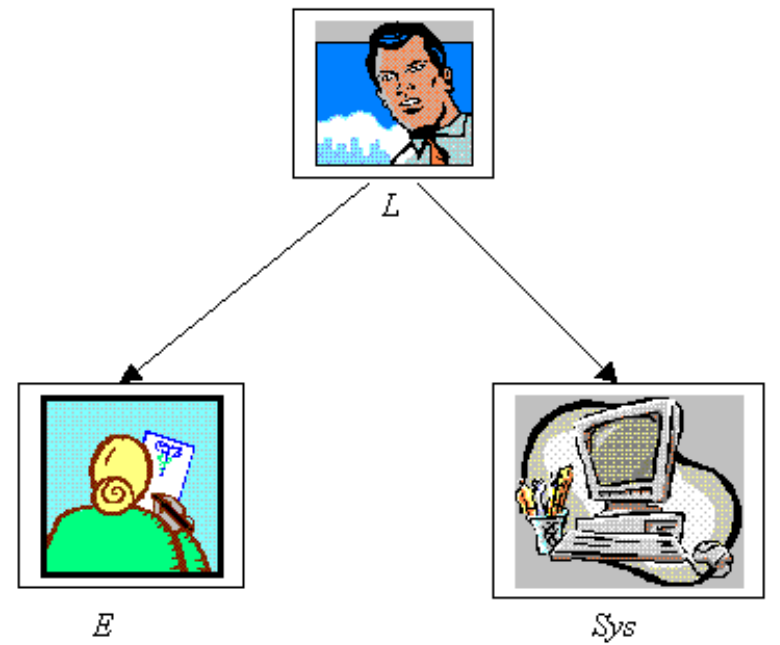

Fig. 5 The experiment control.

- Whether the same conclusion derived both in the system and the existing non modeled domain,

- Whether reducing dependencies effected conclusion differences.

By testing this aspect it can arrive at a conclusion that the commonsense knowledge modeling system works in an agreeable way with a domain expert.

\subsection{Reasoning for Different Conclusion Made between the System and Ayurvedic Expert}

It is expected that overall conclusion about the system and expert modeling in such domain would be same. On this assumption, the evaluation proved that the percentage of same overall conclusion made by the system and the Ayurvedic expert is $77 \%$ (Tables 3 and 4 ).

\subsection{Reasoning for Knowledge Classification Ability in the System}

The system has classified knowledge objectively by giving numerical values (percentages of human constitutions types) in all layman-systems interactions $(100 \%)$, which were not done by Ayurvedic experts in layman-Ayurvedic expert interactions. Therefore Ayurvedic expert could classify knowledge subjectively without giving numerical measurements (fine-tuning ability), which is insufficient to prove fundamentals of Ayurveda. So this enables to justify fine-tuning ability of the system. 
Table 3 System testing: expert vs. system.

\begin{tabular}{llll}
\hline Vata & Pitta & Kapha & Expert_decision \\
\hline 25.71 & 20.71 & 53.57 & KV \\
32.95 & 23.86 & 43.18 & VP \\
39.88 & 23.81 & 36.31 & VP \\
27.65 & 46.1 & 26.24 & KP \\
25.69 & 29.36 & 44.95 & KV \\
33.58 & 24.09 & 42.34 & KV \\
25.71 & 34.28 & 40 & KP \\
32.21 & 31.54 & 36.24 & KV \\
22.51 & 29.8 & 47.68 & KP \\
20.37 & 30.56 & 49.07 & PK \\
30.6 & 35.52 & 33.88 & PK \\
29.71 & 17.39 & 52.9 & KV \\
41.07 & 10.71 & 48.21 & KV \\
34.5 & 32.16 & 33.33 & KV \\
23.46 & 28.57 & 47.96 & PK \\
35.27 & 30.77 & 33.97 & KV \\
42.36 & 36.11 & 21.53 & VP \\
23.01 & 35.71 & 41.27 & PK \\
47.94 & 19.86 & 32.19 & KV \\
14.03 & 35.96 & 50 & PK \\
19.15 & 36.88 & 43.97 & PK \\
22.46 & 25.36 & 52.17 & PK \\
40.47 & 26.78 & 32.74 & PK \\
30.28 & 29.58 & 40.14 & KV \\
12.71 & 44.92 & 42.37 & PK \\
11.18 & 40 & 48.82 & PK \\
11.24 & 40.24 & 48.52 & PK \\
23.44 & 26.9 & 49.66 & PK \\
17.09 & 36.75 & 46.15 & KV \\
33.09 & 30.15 & 36.76 & KV \\
\hline & & & \\
\hline
\end{tabular}

9.3 Reasoning for Further Analysis Ability in the System

System has given further explanations for derived answers such as possible mental diseases, predominated constitute type, in dominated constitute type and it was about $100 \%$ of system-user interactions. But Ayurvedic expert could not give further analysis about derived answers as subjective measurement and it was about $0 \%$ of Ayurvedic expert- user interactions.

This is proved by the user preference of the system in reasoning the derived answers.

It has been observed that only $77 \%$ of conclusions made by the sample have been emulated with both system and Ayurvedic expert. Difference of $23 \%$ has
Table 4 Comparission of conclusions: expert vs. system.

\begin{tabular}{lllll}
\hline Vata & Pitta & Kapha & Expert_decision & Conclusion \\
\hline 25.71 & 20.71 & 53.57 & KV & matched \\
33.58 & 24.09 & 42.34 & KV & matched \\
25.71 & 34.28 & 40 & KP & matched \\
32.21 & 31.54 & 36.24 & KV & matched \\
22.51 & 29.8 & 47.68 & KP & matched \\
20.37 & 30.56 & 49.07 & PK & matched \\
30.6 & 35.52 & 33.88 & PK & matched \\
29.71 & 17.39 & 52.9 & KV & matched \\
41.07 & 10.71 & 48.21 & KV & matched \\
34.5 & 32.16 & 33.33 & KV & matched \\
23.46 & 28.57 & 47.96 & PK & matched \\
35.27 & 30.77 & 33.97 & KV & matched \\
23.01 & 35.71 & 41.27 & PK & matched \\
47.94 & 19.86 & 32.19 & KV & matched \\
14.03 & 35.96 & 50 & PK & matched \\
19.15 & 36.88 & 43.97 & PK & matched \\
22.46 & 25.36 & 52.17 & PK & matched \\
30.28 & 29.58 & 40.14 & KV & matched \\
12.71 & 44.92 & 42.37 & PK & matched \\
11.18 & 40 & 48.82 & PK & matched \\
11.24 & 40.24 & 48.52 & PK & matched \\
23.44 & 26.9 & 49.66 & PK & matched \\
33.09 & 30.15 & 36.76 & KV & matched \\
\hline & & & &
\end{tabular}

been shown due to model refinement process carried out by the Principal Component Analyzer. This leads to the reduction of the dependency among questions in the questionnaire. In normal consultancy process of classification of humeral constitutions, Ayurvedic expert may ask repeated questions by mistake due to large number of consultations. In current practice Ayurvedic expert can identify constitute type of a patient subjectively. But classifying constitutions type in percentages enhances the system. This leads to convince the fundamentals of Ayurveda according to classification of humeral constitutions. According to fundamentals of Ayurveda in classifying humeral constitution types, it has been stated that all constitutions types consist of a combination. Possible mental diseases that can be happened due to predominated humeral constitution type have been observed. But system gives a chance of handling that part which enhances to measure the effect of minimum 
constitution type for a mental disease.

\section{Discussion}

In this approach the domain experts are encouraged to present their knowledge to construct more useful questionnaire. However, different experts may propose different questionnaire since their emphasis of domain knowledge is different. At present the system is based on one expert view of the domain knowledge. Eventually PC analysis will be done on that knowledge and generate the appropriate fuzzy membership functions for classifying knowledge. Reasoning for classified knowledge has been achieved by expert system technology.

The key feature required to test in the system the authors developed is whether the system represents modeling commonsense knowledge, which is considered as inconsistent process in real world applications. At the model refinement stage 25 principal components have been identified using 100 laymen. This was due to the dependencies among questions in the questionnaire. Further, this leads to the reduction of dependencies among the questions in the questionnaire. The evaluation of model for modeling commonsense knowledge, was carried out using a group of 30 laymen by an Ayurvedic expert. The knowledge classification process has been done in terms of objective measurement. The selected evaluation of recognition of humeral constitutions has been classified in to vata, pitta and kapha in percentages (objective measurement). This stage is directly integrated with proceeding model refinement stage. Reasoning for objective measurement has been further investigated. At this stage the authors concluded that overall investigation of humeral constitutions leads to several approaches such as possible mental diseases, dominated humeral constitution type. It was identified that modeling of commonsense knowledge in existing expert systems is not sufficient.

The overall system facilitates for a user in modeling tacit knowledge that has not been modeled in existing mechanisms. This is considered as inconsistency and unable to extract useful conclusions. Further total observations defined on a philosophical theory, which is based on commonsense knowledge, cannot be obtained. In the evaluation process of the system, classification of humeral constitutions in current practice of Ayurvedic medicine has been taken into account. The current practice of classification of humeral constitutions is based on Ayurvedic theory called prakuthi pariksha. But certain observations defined on this theory cannot be obtained.

The performances of the system have been compared with an Ayurvedic expert using the observations derived from a practice of classification of humeral constitutions. Similar type of conclusions made by both system and Ayurvedic expert is about $77 \%$. Ayurvedic expert identified only a humeral constitution type where as system identified total humeral constitutions types in percentages. Further reasoning for derived conclusions has given only by the system such as possible mental diseases, constitutions types and predominance constitution type.

\section{Conclusions}

The commonsense knowledge modeling system in clinical psychology for Ayurvedic medicine can be used for recognition of human constituents and its possible mental diseases. Knowledge modeling approach for modeling commonsense knowledge in psychological assessment enables holistic approach for clinical psychology. The system has been reached the objectives of finding type of dosa (constituent type: vata, pitta, kapha) in percentages, dominant type of dosa and possible metal disease based on type of dosa.

The users of the system are not expected to hold knowledge in statistical or artificial intelligence techniques. This system can also maintain history of patients for research related human constitutes. It should be noted that with the help of Artificial Intelligence technologies the authors have improved 
the correctness of the decision making process in relation to the use of traditional questionnaire for psychological assessment in clinical psychology integrated on Dosa in which one of the three root-causes of unskillful or un-wholesome actions (akusala-mula) and prakurthi pariksha in clinical psychology of Auyvedic medicine. This eliminates the inconsistencies and repetitiveness of answers and also provides a means for explanation of reasons for answers. The system can be further developed as a comprehensive learning system with access to the Internet. Evaluation of the system has shown 77\% accuracy.

\section{References}

[1] A.W.P. Guruge, Fascicle 4: Dhammadhatu-Dvesa, Encyclopedia of Buddhism, Government of Sri Lanka, Sri Lanka, 1989.

[2] J. Liyanaratne, Nosology in Ayurveda: Data from a Pali Canonical Text, Buddhism and Traditional Medicine in Sri Lanka, Kelaniya University Press, Ragama, Sri Lanka, 1999.

[3] A. Myint, Theravada treatment and psychotherapy: an ecological integration of Buddhist tripattie practice and western relational analysis, Ph.D. Thesis, Murdock University, Australia, 2007.

[4] L. Cirillo, B. Kaplan, S. Wapner, Emotions in Ideal Human Development, Clark University, U.K., 1989.

[5] P. Ratanakul, Buddhism, health and disease, Eubios Journal of Asian and International Bioetics 15 (2004) 152-154.

[6] D. Bhugra, Psychiatry and Region: Context, Consensus, and Controversies, Routledge, London \& New York, 1986.

[7] J. Pickering, The Authority of Experience: Essays on Buddhism and Psychology, Routledge, London \& New York, 1987.

[8] T. Kariyavasam, Buddhism and Psychology, Routledge, London \& New York, 2003.

[9] F.J. Varalela, E.T. Thompson, Eleaner Rosch, The Embodied Mind, The MIT Press, Massachusetts, United States, 1999.

[10] S.N. Tripathi, Clinical Diagnosis, Science and Philosophy of Indian Medicine, Shree Beldyanath Ayurved Bhawan Ltd, Calcutta, India, 1978.

[11] Depression, causes, types, treatment of vata, pitta and kapha [Online], http://depressionhelp.in/depressiondetail.htm.

[12] Alternative Medicine Therapies: Ayurveda Medicine
[Online], http://library.thinkquest.org/24206/ayurvedamedicine.html.

[13] Vata Pitta Kapha [Online], http://www. ayurvedicdietsolutions.com/Vata-Pitta-Kapha.php.

[14] R. Vega, Ayurvedic \& Western approaches to the treatment of schizophrenia, CA College of Ayurveda, [Online], http://www.ayurvedacollege.com/ articles/\%E1\%B9\%A3tudents/schizophrenia\#Overview.

[15] C.R. Reynolds, Psychological Assessment, American Psychological Association, Washington, DC, 2010.

[16] G.P.Dubey, The Physiological Concepts in Indian Medicine, Science and Philosophy of Indian Medicine, Shree Beldyanath Ayurved Bhawan Ltd, Calcutta, India, 1978.

[17] The dosha quiz: an introduction to your Ayurvedic lifestyle from the Chopra center for wellbeing [Online], http://doshaquiz.chopra.com.

[18] Self-test [Online], http://tridosha.com/self-test.

[19] This quiz should help lead you in the right direction [Online], http://www.whatsyourdosha.com/ quiz/form1. php.

[20] Banyan Botanicals Your resource for Ayurveda and premium quality Ayurvedic products [Online], http://www.banyanbotanicals.com.

[21] D.L. Paul, Collaborative activities in virtual settings: a knowledge management perspective of telemedicine, Journal of Management Information Systems 22 (4) (2006) 143-176.

[22] A. Dwivedi, R.K. Bali, A.E. James, R.N.G. Naguib, Telehealth systems: considering knowledge management and ICT issues, in: Proceedings of the 23rd Annual International Conference of the IEEE, 2001, pp. 3614-3617.

[23] K. Chris, Effective Virtual Teams through Communities of Practice, Strathclyde Business School Management Science Working Paper No. 2000/9, University of Strathclyde, United Kingdom, 2000.

[24] Julie Parker, Enrico Coiera, Improving clinical communication: a view from psychology, JAMIA 7 (5) (2000) 453-461.

[25] R. Lenz, M. Reichert, IT support for healthcare processes-premises, challenges, perspectives, Data \& Knowledge Engineering 61 (1) (2007) 39-58.

[26] L. Fallowfield, V. Jenkins, Effective communication skills are the key to good cancer care, European Journal of Cancer 35 (11) (1999) 1592-1597.

[27] M. Stefanelli, The role of methodologies to improve efficiency and effectiveness of care delivery processes for the year 2013, International Journal of Medical Informatics 66 (1-3) (2002) 39-44.

[28] A. Mark, L. Fagan, D. Combs, H. Edward, Use of a domain model to drive an interactive knowledge editing 


\section{Development of Commonsense knowledge Modeling System for Psychological Assessment in Clinical Psycho}

tool, International Journal of Man-Machine Studies 26 (1) (1987) 105-121.

[29] M. Ramoni, M. Stefanelli, L. Magnani, G. Barosi, An epistemological framework for medical knowledge-based systems, Systems, Man and Cybernetics, IEEE Transactions on 22 (6) (1992) 1361-1375.

[30] J.A. Reggia, D.S. Nau, P.Y. Wang, Diagnostic expert systems based on a set covering model, International Journal of Man-Machine Studies 19 (5) (1983) 437-460.

[31] J. Gennari, M. Musen, R. Fergerson, E. William, The evolution of Protégé: an environment for knowledge based systems development, International Journal of Human-Computer Studies 58 (1) (2003) 89-123.

[32] E.H. Shortliffe, S.G. Axline, B.G. Buchanan, T.C. Merigan, S.N. Cohen, An Artificial Intelligence Program to Advise Physicians Regarding Antimicrobial Therapy, Computers and Biomedical Research 6 (6) (1973) 544-560.

[33] D.S.K Mendis, A.S. Karunananda, U. Samarathunga, U. Ratnayaka, Tacit Knowledge modeling in Intelligent Hybrid systems, in: Second International Conference on Industrial and Information Systems, Peradeniya, Aug. 9-11, 2007.

[34] D.S.K. Mendis, A.S. Karunananda, U. Samarathunga, A computer model for diagnosis of human constituents, in: International Conference on Information and Automation, Colombo, 2006.

[35] G. Coppin, A.Skrzyniarz, Human-centered processes: individual and distributed decision support, IEEE Intelligent Systems 18 (4) 2003 27-33.

[36] R.D. Zielstorff, Online practice guidelines, JAMIA 5 (1988) 227-236.

[37] K.Rajeev, Integrating knowledge bases in expert system shells: an open system approach, International Journal of Computer Application in Technology 8 (1-2) (1995) 78-89.

[38] D.S.K. Mendis, A.S. Karunananda, U. Samarathunga, Multi-Techniques integrated tacit knowledge modelling system, International Journal of Information Technology 9 (2004) 265-271.

[39] G.A. Boy, Intelligent Assistant Systems, Academic Press Inc., San Diego, 1991.

[40] R. Dawson, Developing Knowledge-Based Client Relationship, Butterworth Heinemann, Oxford, United Kingdom, 2001.

[41] Knowledge Modelling in [Online], http://kmi.open.ac.uk/knowledge-modelling/people.html.

[42] Xpert Rule Knowledge Builder [Online], http://www.attar.com.

[43] D.S.K. Mendis, A.S. Karunananda, U. Samarathunga, U. Ratnayake, An approach to the development of commonsense knowledge modelling systems for disaster management, Artificial Intelligence Review 28 (2007) 179-196.
[44] D.S.K. Mendis, A.S. Karunananda, U. Samarathunga, A commonsense knowledge modeling system for psychological assessment in clinical psychology for diagnosis of dosa, in: 6th National Conference on Buddhist Studies, Sri Lanka, 2010.

[45] D.S.K. Mendis, A.S. Karunananda, U. Samarathunga, Statistical fuzzy inference system for classifying human constituents, in: 5th ICIAFS (International Conference on Information and Automation for Sustainability), Colombo, Sri Lanka, 2010, pp. 51-57.

[46] J. Liu, R. Shiffman, Operationalization of clinical practice guidelines using fuzzy logic, in: Proceedings of AMIA Ann. Fall Symp., American, 1997, pp. 283-287.

[47] W. Jim, B. Gleb, V.Z. Berend, Fuzzy logic in clinical practice decision support systems, in: Proceedings of the 33rd Hawaii IEEE International Conference on System Sciences, 2000.

[48] Topics in statistical data analysis [Online], http://home.ubalt.edu/ntsbarsh/stat-data/topics.htm.

[49] Bayesian inference [Online], http://en.wikipedia.org/wiki/ Bayesian_inference.

[50] V. Noak, Discovering the world with Fuzzy Logic, Springer-Verlag Company, Heidelberg, New York, 2000, pp. 3-50.

[51] Bart Kosko, Neural Networks and Fuzzy Systems: A Dynamical Systems Approach to Machine Intelligence, Englewood Cliffs, NJ, Prentice Hall, USA, 1992, p. 265.

[52] Y. Hayashi, E. Tazaki, K.K. Yoshida, P. Dey, Medical diagnosis using simplified multi-dimensional fuzzy reasoning, in: Proceedings of IEEE 1988 International Conference on Systems, Man and Cybernetics, Beijing, China, 1988.

[53] G. Kolousek, The system architecture of an integrated medical consultation system and its implementation based on fuzzy technology, Doctoral Thesis, Technical University of Vienna, Austria, 1997.

[54] C. Chatfied, Introduction to Multivariate Analysis, Chapman and Hall, London and New York, 1996.

[55] J.K. George, B.Yuan, Fuzzy Sets and Fuzzy Logic, Prentice Hall of India Pvt. Ltd., New Delhi, India, 1995, pp. 280-300.

[56] L.L. Jonson, Expert System Architectures, Kopan Page Limited, London, 1988.

[57] D. Richards, P. Bush, Measuring, Formalizing and modeling tacit knowledge, in: IEEE/Web Intelligence Conference (WI-2003), Beijing, China, 2003.

[58] M. Sugeno, Industrial Applications of Fuzzy Control, Elsevier Science Pub. Co., New York, 1985.

[59] M.C. Morogan, SPSS for Windows, Release 8.0.0, DSV KTHSU, Sweden, 1997.

[60] D. Westwood, Flex Reference Guide, Logic Programming Associates Ltd, U.K., 1990-1996. 